\title{
Immunohistochemical localisation of rabbit haemorrhagic disease virus VP-60 antigen in early infection of young and adult rabbits
}

\author{
J. M. PRIETO*, F. FERNANDEZ, V. ALVAREZ, A. ESPI, J. F. GARCÍA MARÍN†, M. ALVAREZ†, \\ J. M. MARTÍN
}

\author{
Laboratorio de Sanidad Animal, 33299 Gijón, Spain, †Departamento de Patología Animal: Sanidad Animal, Facultad de \\ Veterinaria, Universidad de León, Spain, $¥$ Departamento de Bioquímica y Biología Molecular, \\ Universidad de Oviedo, 33006 Oviedo, Spain
}

\begin{abstract}
SUMMARY
This study evaluated the time course distribution of rabbit haemorrhagic disease virus (RHDV) structural protein VP60 in tissues from experimentally infected rabbits from three different age groups. Viral VP60 antigen could not be detected in tissue samples from animals under four weeks, and only a few hepatocytes (0.01 to 0.2 per cent) were stained in the 6-week-old animals. A 6week-old rabbit euthanised at 72 hpi showed VP60-labelling in hepatocytes and macrophages close to areas of inflammation. Viral VP60 antigen was detected as early as 12 hpi in a few hepatocytes ( 0.03 per cent) from adult animals. Within this age group, the extent of hepatocyte labelling considerably increased at 18 ( 3.0 per cent), 24 ( 25.5 per cent), 36 (50 per cent) and 48 (60 per cent) hpi. Extrahepatic viral VP60 antigen was also detected at 36 and 48 hpi in spleen macrophages and lymphocytes from adult rabbits. These findings support the hypothesis that the hepatocyte is the only cell type in the liver able to support RHDV replication almost immediately after viral infection. (C) 2000 Harcourt Publishers Ltd
\end{abstract}

VIRAL haemorrhagic disease of rabbits (RHD) is an acute highly fatal disease of European wild and domestic rabbits, which was first reported from the People's Republic of China in 1984 (Liu et al 1984). The causative agent of RHD has been classified as a member of Caliciviridae (Ohlinger et al 1990, Parra and Prieto 1990). The disease evolves rapidly to death within 48 to 72 hours after infection in about 90 per cent of the cases. The most consistent pathological findings are severe necrotising hepatitis (Marcato et al 1991) and disseminated intravascular coagulation (DIC) (Ueda et al 1992, Park et al 1995). More recently it has been described that infection-induced liver cell death is due to apoptosis (Alonso et al 1998). Viral antigen was detected by immunohistological techniques using antisera from naturally infected animals in hepatocytes, macrophages, circulating monocytes and reticuloendothelial cells in liver, lung, spleen and lymph nodes (Marcato et al 1991, Carrasco et al 1991a, Park et al 1992, Park and Itakura 1992, Stoercklé-Berger et al 1992, Alonso et al 1998). It is recognised that young rabbits are not susceptible to the disease (Xu and Chen 1989, Marcato et al 1991), the mechanism of this lack of susceptibility, and the periodic viral tropism and pathogenesis remain partly unknown.

In this paper we describe the immunohistological localisation of the RHDV VP60 protein at early infection times in tissues from experimentally infected adult and young

*Corresponding author rabbits, using a guinea pig polyclonal antibody raised against the recombinant VP60 protein from RHDV.

\section{MATERIALS AND METHODS}

\section{Experimental infections}

Eighteen New Zealand White rabbits were used in this study, distributed in three groups of six animals; group A: 3-weeks-old; group B: 6-weeks-old and group C: 9-weeksold. Fifteen rabbits were injected intramuscularly with $2 \times 10^{4}$ haemagglutination units of RHDV isolate Ast/89. One animal from each group was euthanised by intravenous injection of sodium pentobarbital at 12, 18, 24, 36 and 72 hours postinfection (hpi), except one rabbit of group $\mathrm{C}$ which died spontaneously at $48 \mathrm{hpi}$. Three rabbits (one per group) were not exposed to the virus and served as controls.

\section{Anti-VP60 serum}

The VP60-antiserum was prepared by hyperimmunising guinea pigs with the RHDV VP60 protein produced using a recombinant baculovirus (Marín et al 1995). Overall, four injections were administered on days 1, 3, 6 and 9 and a large blood sample was drawn on day 14.

\section{Histology and immunohistochemistry}

At necropsy, samples of liver, spleen, kidney, lung, intestine, thymus, heart and brain were taken from all rabbits and 
fixed in 10 per cent neutral buffered formalin. Paraffinembedded tissues were stained for histological analysis with haematoxylin-eosin (HE). For the immunohistochemical study, 5- $\mu \mathrm{m}$ tissue sections were cut and immunostained using the peroxidase-antiperoxidase (PAP) method (Sternberger et al 1970). Endogenous peroxidase was blocked by immersing sections for 10 minutes in freshly made 3 per cent hydrogen peroxide in methanol, followed by 0.1 per cent trypsin treatment in calcium cloride $(\mathrm{pH}$ $7 \cdot 8$ ) for 10 minutes at $37^{\circ} \mathrm{C}$. Sections were washed in running tap water, rinsed with Tris-buffered saline $\mathrm{pH} 7.6$ containing 1.6 per cent sodium chloride (TBS), and incubated with a mixture of 10 per cent $(\mathrm{v} / \mathrm{v})$ normal goat serum and 3 per cent $(\mathrm{w} / \mathrm{v})$ bovine serum albumin in TBS for 15 minutes. After draining, the sections were incubated overnight at $4{ }^{\circ} \mathrm{C}$ with a guinea pig VP60-antiserum at 1:2000 dilution, which was previously optimised by titration for specific immunolabelling. Several sections from each group served as serum controls by omission of the primary immune serum and substitution with preimmune serum. After washing with TBS, all sections were incubated at room temperature with 1:20 dilution of goat anti-guinea pig immunoglobulins (Sigma), then with guinea pig PAP complex (1:400), each for 30 minutes, with a TBS wash between incubations. Diaminobenzidine tetrahydrochloride (DAB) was used to visualise immunocomplexes, and the sections were lightly counterstained with Mayers haematoxylin. The positive cells were counted in 10 randomly chosen fields at a $\times 200$ magnification.

\section{RESULTS}

\section{Histological lesions}

Microscopically, no lesions were found in tissues from control or groups A and B infected rabbits, except for one rabbit in group B, euthanised at $72 \mathrm{hpi}$, which showed a low number of necrotic hepatocytes located at periportal areas. Inflammation with presence of mononuclear cells (lymphocytes, macrophages and plasma cells) was also observed in this animal (Fig 1).

Relevant microscopic abnormalities were observed in the livers from group C rabbits. At $12 \mathrm{hpi}$, only pyknosis and karyorrhesis were observed in individual hepatocytes (Fig 2). At 18 hpi, a small number of necrotic hepatocytes were found associated with neutrophils in the periacinar areas. At $24 \mathrm{hpi}$, hepatocellular karyorrhesis and vacuolar degeneration were observed with a periacinar distribution, necrosis of individual hepatocytes was associated with the presence of neutrophils (Fig 3).

At longer post-infection times, the main lesion observed was coagulation necrosis in a large number of hepatocytes, which showed homogeneous eosinophilia, pyknosis and karyorrhexis. As a consequence of hepatocyte dissociation, liver cords became discontinuous and irregular, neutrophils and Kupffer cells often surrounded damaged hepatocytes and in some areas small foci of hepatic necrosis were observed. Microthrombi were found in small blood vessels from liver, spleen and kidney, a characteristic feature of DIC.

In spleen, particularly in the rabbit that died unexpectedly, karyorrhexis and pyknosis were observed in cells

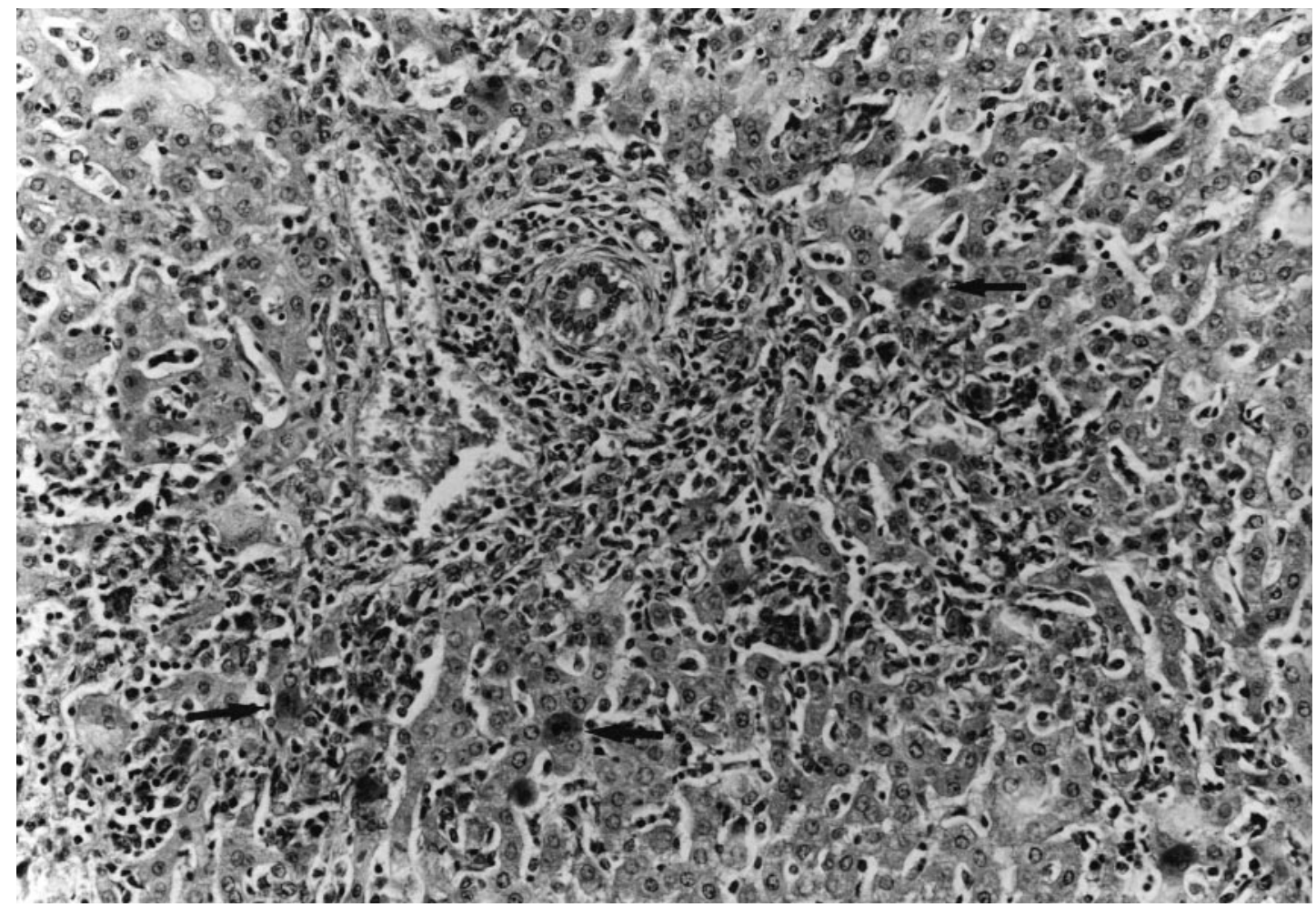

FIG 1: Detection of VP60 antigen in the liver of a six-weeks-old, RHDV-infected rabbit sacrificed at 72 hpi. The arrows indicate the stained hepatocytes at inflammation areas with presence of mononuclear cells. Magnification $\times 200$. 


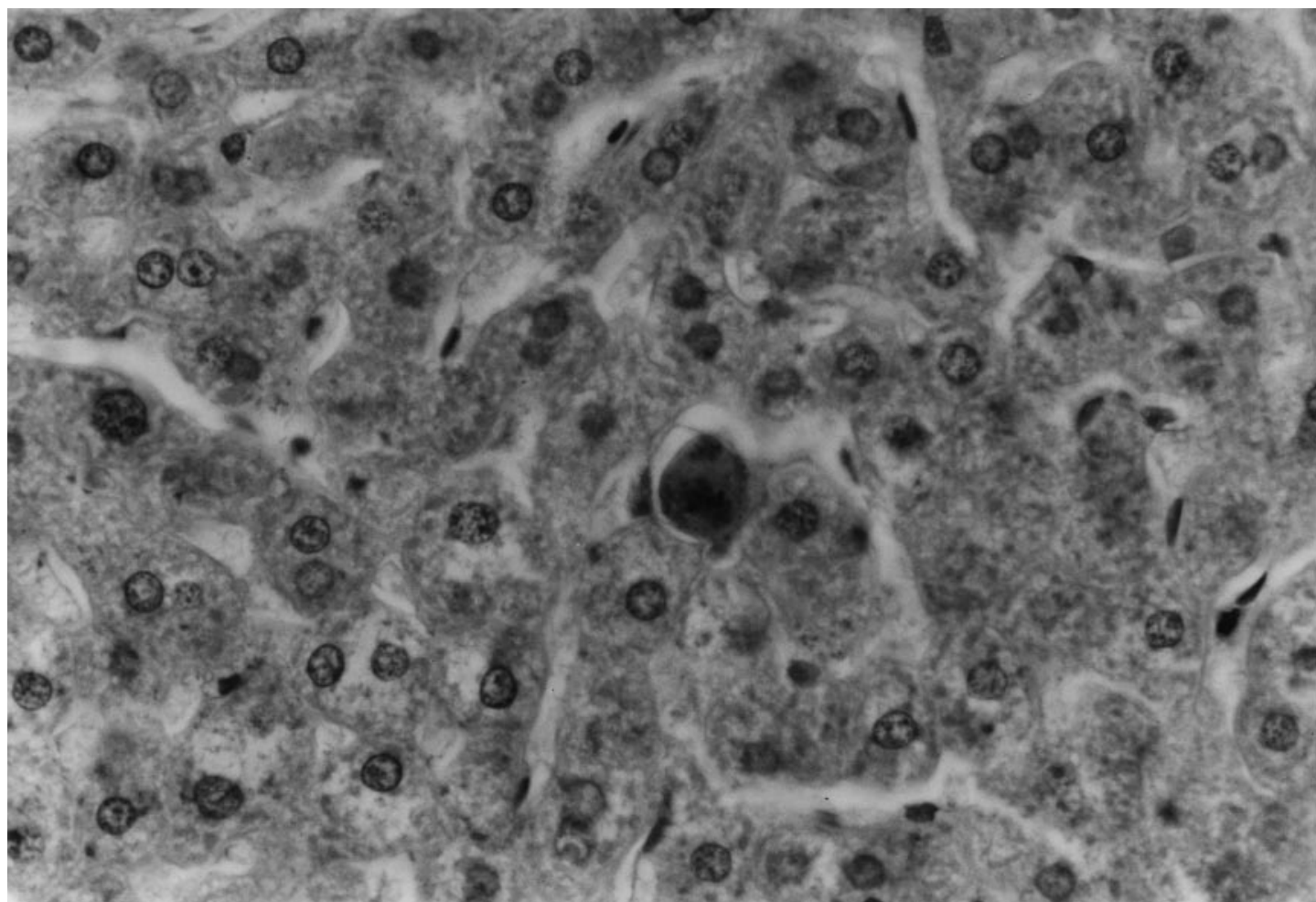

FIG 2: VP60-immunoperoxidase positive staining of a hepatocyte from an adult (group C) rabbit, sacrificed at 12 hpi, showing pyknosis and karyorrhexis. Magnification $\times 400$.

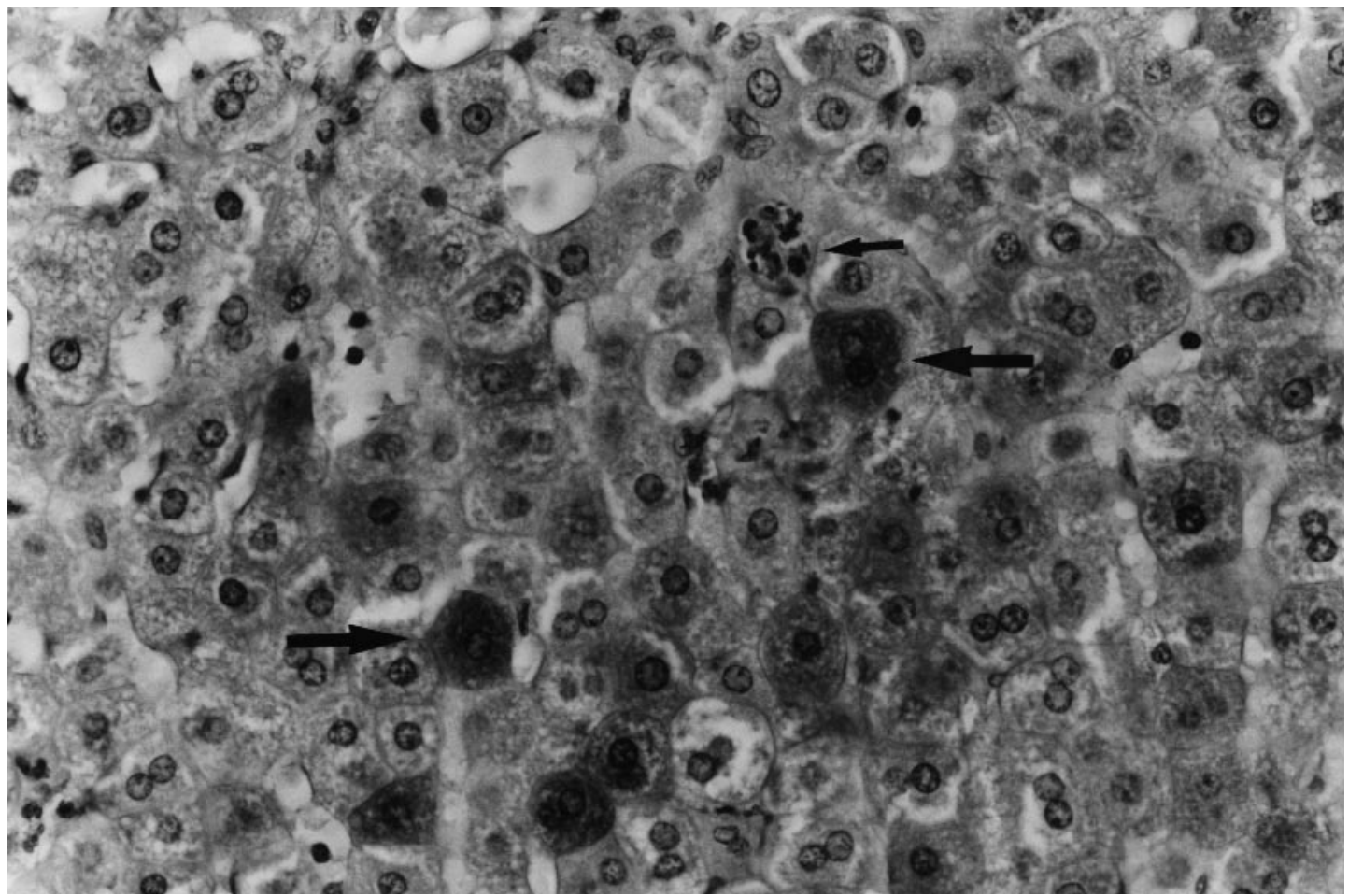

FIG 3: VP60-immunoperoxidase staining in individual hepatocytes (large arrows) from an adult (group C) rabbit, sacrificed at $24 \mathrm{hpi}$, associated with the presence of neutrophils (small arrow). Magnification $\times 400$.

located either in follicular or perifollicular areas, the white pulp was depleted of lymphocytes and the splenic nodules were reduced in size (Fig 4).
In lung, alveolar oedema was the only finding observed. Histological lesions could not be detected in thymus, heart, intestine or brain. 


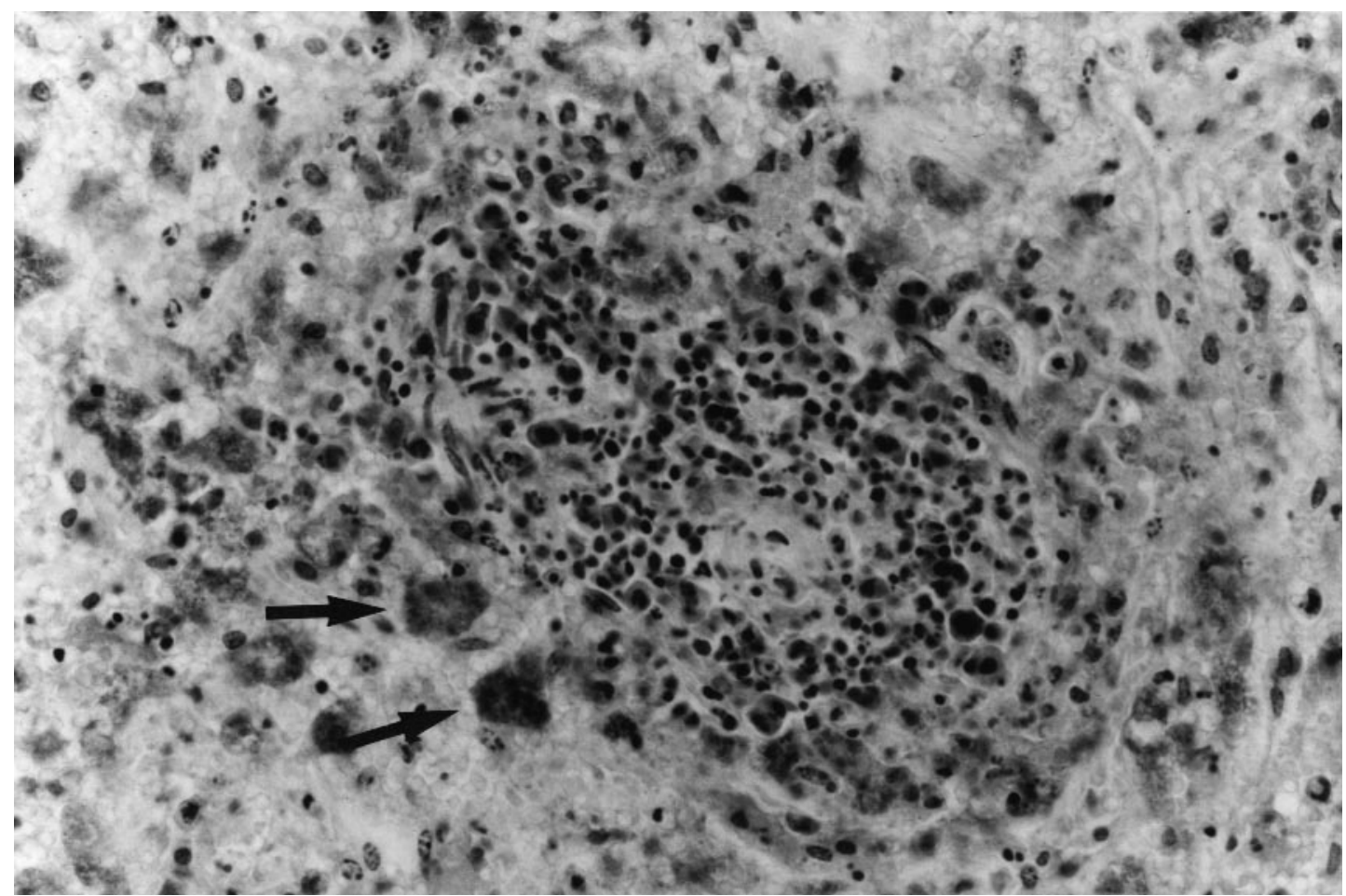

FIG 4: VP60-immunoperoxidase staining in spleen mononuclear cells (arrows) located in perifollicular areas from an adult (group C) rabbit, dead at 48 hpi. Karyorrhesis and pyknosis of follicular cells are observed causing white pulp lymphocyte depletion. Magnification $\times 200$.

\section{Immunohistochemistry}

Viral VP60 antigen was not detected in tissue samples from uninfected control animals. Labelling was not found in any of the RHDV-infected rabbits from group A nor in the samples from group B animals killed at 12 hpi. Viral VP60 antigen was detected in $0 \cdot 1,0 \cdot 2$ and 0.01 per cent of intact hepatocytes from group B killed at 18, 24 and 36 hpi respectively. Some labelling was scattered in macrophages and hepatocytes, close to areas with inflammation, in the rabbit sacrificed at 72 hpi (Fig 1). No labelling was found in lungs, spleen, heart, intestine, thymus or brain.

Viral VP60 antigen was detected as early as $12 \mathrm{hpi} \mathrm{in} 0.03$ per cent of hepatocytes from group $\mathrm{C}$ rabbits, some associated with pyknosis and karyorrhexis (Fig 2). In the samples taken from adult rabbits at $18 \mathrm{hpi}, 3$ per cent of the hepatocytes were infected (Fig 5a). The extent of labelling increased in this group of animals at 24 hpi (over 25 per cent), in which the labelled hepatocytes were mainly found in the periportal and midzonal areas, coinciding with the distribution of degenerate and necrotic hepatocytes, although most of the infected cells were not necrotic (Fig 5b). Labelling was not found in other organs.

At 36 and 48 hpi, the liver revealed extensive (50 to 60 per cent) viral VP60-antigen immunolabelling (Fig 5c). It was characteristic to find numbers of virally infected hepatocytes in which signs of necrosis were absent. Positive cellular staining was progressively lost as necrotic changes occurred, namely, cytoplasmic eosinophilia and nuclear fragmentation. In addition, immunolabelling was observed in neutrophils often surrounding damaged hepatocytes (Fig 3). Viral VP60 antigen was widely detected in spleen, most of the label was found in macrophages and lymphocytes of the red pulp and in perifolicullar areas (Fig 4). In the rabbit that died at $48 \mathrm{hpi}$, viral VP60-antigen was also found in the cytoplasm of a small number of lung alveolar macrophages, circulating monocytes, and in the glomerular mesangial cells of the kidney.

\section{DISCUSSION}

The presence of viral VP60 antigen within the hepatocytes from infected rabbits confirms the replication of this virus in the liver and is entirely consistent with the results reported in previous studies (Carrasco et al 1991b, Park and Itakura 1992, Park et al 1992, Stoercklé-Berger et al 1992, Alonso et al 1998). In contrast, in this work no specific VP60-labelling was found in liver reticuloendothelial cells nor in extrahepatic tissues from adult rabbits, experimentally infected by intramuscular injection with RHDV and killed at 12, 18 and $24 \mathrm{hpi}$. A possible explanation for this observation is that infection of reticuloendothelial cells and macrophages might only occur at later disease stages or in not susceptible young rabbits (Marcato et al 1991). Accordingly, labelling was found in a six-week-old rabbit, scattered in macrophages close to inflammation areas, a sign compatible with a subacute type of RHD (Nowotny and Steineck 1991).

The pattern of PAP VP60-labelling recorded in the present study showed that the viral antigen can be found within the hepatocyte as early as 12 hpi, clearly demonstrating that hepatocytes can support RHDV replication almost 

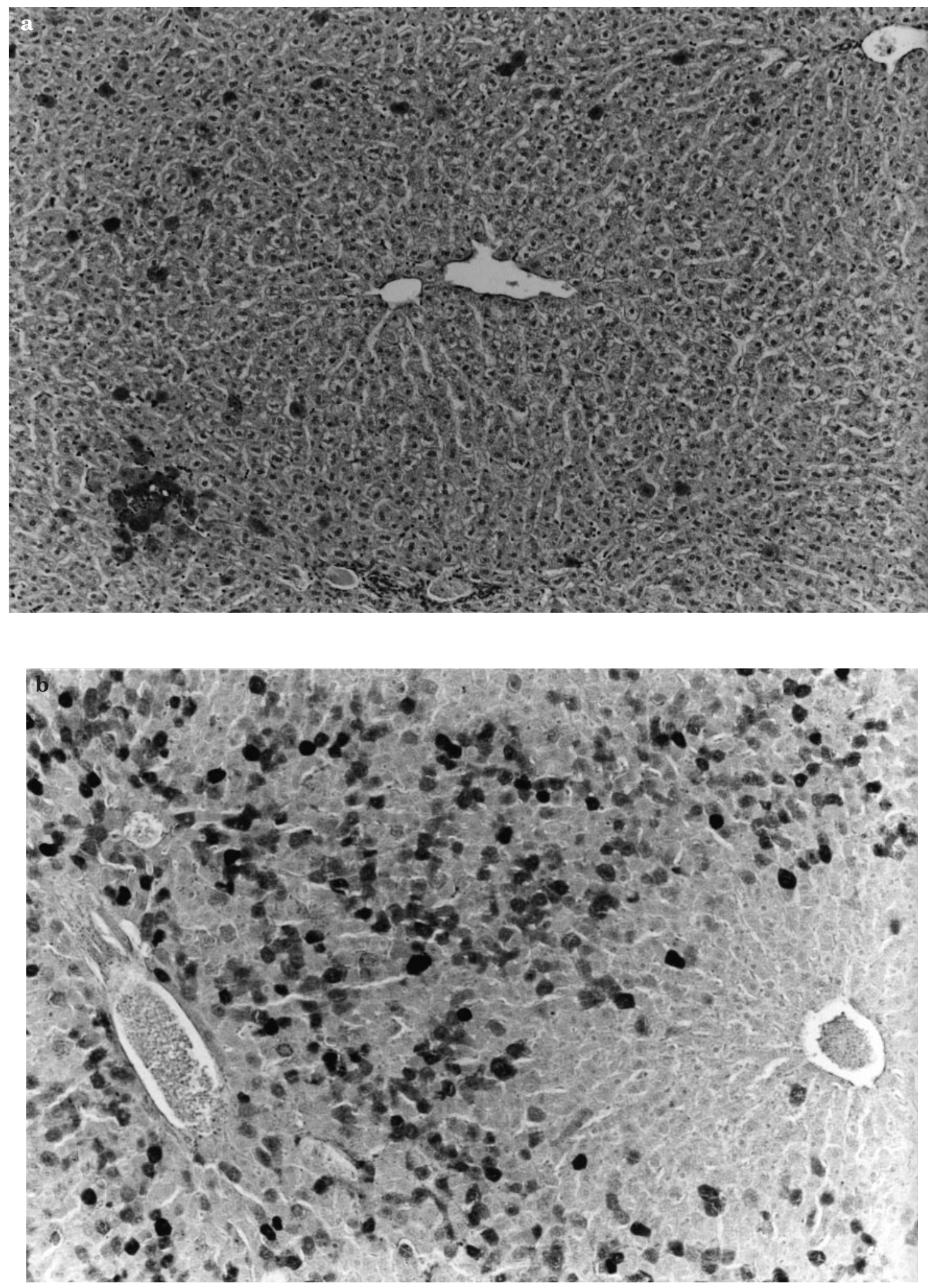

FIG 5: Perilobular VP60-immunoperoxidase staining in hepatocytes from adult rabbits at $18 \mathrm{hpi} \mathrm{(a),} 24 \mathrm{hpi} \mathrm{(b).} \mathrm{(Fig} \mathrm{5c,} \mathrm{over)}$

immediately after viral infection. After 36 hours the liver revealed extensive immunolabelling of viral VP60 antigen, accompanied by severe destruction of liver tissue. The strong positive reaction for VP60 antigen detected in intact hepatocytes, as well as the sharp decrease of the labelling observed paralleling cell death, substantial cell loss and tissue destruction, distinctively suggested a rapid disease progression and increased virus load in the liver. 


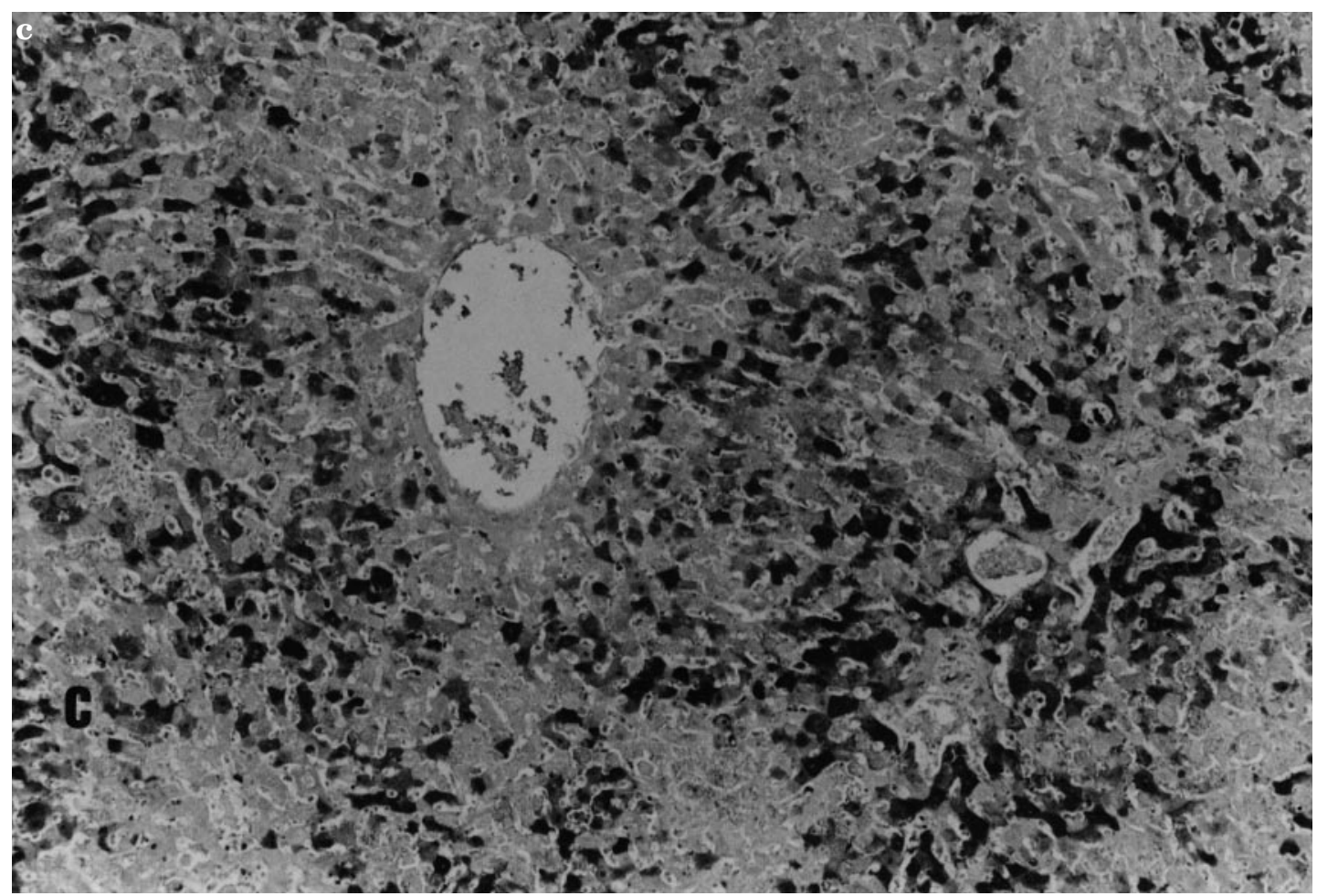

FIG 5: Perilobular VP60-immunoperoxidase staining in hepatocytes from adult rabbits at 36 hpi (c). Magnification $\times 200$.

In contrast to the observations made in the present study, Alonso et al (1998) were not able to detect viral VP60 protein in infected rabbits killed at 12 and 24 hpi by Western-blot and immunohistochemistry, using a hyperimmune anti-RHDV rabbit serum. This qualitative difference might be explained by the use of different assay conditions. It is reasonable to speculate that the use of the guinea pig primary antiserum, an animal species different from the rabbit, could be crucial to obtain a high sensitivity staining (J.M. Prieto, unpublished data). However it seems clear, as reported previously by others (Park and Itakura 1992), that the primary infection occurred at the periportal hepatocytes, extending in a few hours to the midzonal area and finally invading the hepatocytes from the periacinar area.

Extrahepatic viral VP60 antigen was detected at 36 and $48 \mathrm{hpi}$ in splenic macrophages and this might indicate viral replication in this cell type. Alternatively, the cytoplasmic localisation and time course of the antigen labelling could have resulted from phagocytic activity rather than from RHDV replication. This latter hypothesis was also supported by the fact that the majority of stained macrophages were localised in the sinus areas of the spleen, where sorting and processing is carried out by the macrophages to remove injured cells (Schmidt et al 1983).

In previous studies on RHDV pathogenesis, liver tissue destruction has been associated with hepatocyte apoptosis (Alonso et al 1998). Morphologically, apoptosis is characterised by chromatin condensation and aggregation, cellular and nuclear shrinkage and lack of an inflammatory response. The pattern of lesions reported in the present study, concerning hepatocytes and spleen lymphocytes, are both compatible with apoptotic processes.

Disseminated intravascular coagulation (DIC) has been widely reported in different organs from RHD-infected rabbits that have died (Marcato et al 1991, Fuchs and Weissenböck 1992, Ueda et al 1992). In this study, DIC was only found in liver, spleen and kidney from two adults rabbits, one sacrificed at $36 \mathrm{hpi}$ and another that died spontaneously at $48 \mathrm{hpi}$. In addition, viral VP60 antigen could not be detected in damaged endothelial cells indicating either that DIC may only be activated during late stages of peracute forms of RHD with severe tissue damage, or that RHDV infection is not directly associated with the development of DIC. It is also possible that the severe hepatic damage might interfere with clearance of activated clotting factors contributing to the occurrence of DIC.

In the present study, viral VP60 antigen was not detected in tissues from rabbits under four weeks of age. It has been described previously that young rabbits are not susceptible to infection with RHDV and that their resistance to experimental infection is not mediated by passively acquired maternal antibodies (Rodak et al 1991). This resistance to infection decreased rapidly after four weeks of age and natural disease is rarely seen in rabbits less than two months of age. In this study a small number of hepatocytes in sixweek-old rabbits supported viral replication, regardless of the infection time, possibly indicating that the onset of changes in the liver structure and function may be a determinant for RHDV infectivity. 


\section{ACKNOWLEDGEMENTS}

We would like to thank Drs. Ana Navarro and Jorge Tolivia for their skilled technical assistance. This work was supported in part by grant DGES, PB96-0552-C01.

\section{REFERENCES}

ALONSO, C., OVIEDO, J.M., MARTÍN-ALONSO, J.M., DÍAZ, E., BOGA, J.A. \& PARRA, F. (1998) Programed cell death in the pathogenesis of rabbit hemorrhagic disease. Archives of Virology 143, 321-332.

CARRASCO, L., RODRÍGUEZ, F., MARTÍN DE LAS MULAS, J., SIERRA, M.A., GÓMEZ-VILLAMANDOS, J.C. \& FERNÁNDEZ, A. (1991a) Pulmonary intravascular macrophages in rabbits experimentally infected with rabbit haemorrhagic disease. Journal of Comparative Pathology 105, 345-352.

CARRASCO, L., RODRÍGUEZ, F., MARTÍN DE LAS MULAS, J., WOHLSEIN, P., \& FERNÁNDEZ, A. (1991b) Immunohistological diagnosis of rabbit haemorrhagic disease in experimentally infected rabbits in Spain. Journal of Veterinary Medicine 38, 552-555.

FUCHS, A. \& WEISSENBÖCK, H. (1992) Comparative histopathological study of rabbit haemorrhagic disease (RHD) and European brown hare syndrome (EBHS). Journal of Comparative Pathology 107, 103-113

LIU, S.J., XUE, H.P., PU, B.Q. \& QUIAN, N.H. (1984) A new viral disease in rabbits. Animal Husbandry and Veterinary Medicine 16, 253-255.

MARCATO, P.S., BENAZZI, C., VECCHI, G., GALEOTTI, M., DELLA SALDA, Y., SARLI, G. \& LUCIDI, P. (1991) Clinical and pathological features of viral haemorrhagic disease of rabbits and the European brown hare syndrome. Revue Scientifique et Technique, Office International des Épizooties 10, 371-392.

MARÍN, M.S., MARTÍN ALONSO, J.M., PÉREZ, L.I., BOGA, J.A., ARGÜELLOVILLARES, J.L., CASAIS, R., VENUGOPAL, K., JIANG, W., GOULD, E.A. \& PARRA, F. (1995) Immunogenic properties of rabbit haemorrhagic disease virus structural protein VP60 expressed by a recombinant baculovirus: an efficient vaccine. Virus Research 39, 119-128.
NOWOTNY, N. \& STEINECK, T.H. (1991) Epidemiology of Rabbits Haemorrhagic Disease (RHD) and European Brown Hare Syndrome (EBHS) in Austria. Proceeding 2nd Congress of the European Society for Veterinary Virology, Uppsala, Sweden.

OHLINGER, V.F., HAAS, B., MEYERS, G., WEILAND, F. \& THIEL, H.-J. (1990) Identification and characterisation of the virus causing rabbit haemorrhagic disease. Journal of Virology 64, 3331-3336.

PARK, J.H. \& ITAKURA, C. (1992) Detection of rabbit haemorrhagic disease virus antigen in tissues by immunohistochemistry. Research in Veterinary Science 52, 299-306.

PARK, J.H., OCHIAI, K. \& ITAKURA, C. (1992) Detection of rabbit haemorrhagic disease virus particles in the rabbit liver tissues. Journal of Comparative Pathology 107, 329-340.

PARK, J.H., LEE, Y. \& ITAKURA, C. (1995) Pathogenesis of acute necrotic hepatitis in rabbit hemorrhagic disease. Laboratory of Animal Science 45, 445-449.

PARRA, F. \& PRIETO, M. (1990) Purification and characterization of a calicivirus as the causative agent of lethal hemorrhagic disease in rabbits. Journal of Virology 64, 4013-4015.

RODAK, L., SMID, B. \& VALICEK, L. (1991) Application of control measures against viral haemorrhagic disease of rabbits in the Czech and Slovak Federal Republic. Revue Scientifique et Technique, Office International des Épizooties 10, 513.

SCHMIDT, E.E., MACDONALD, I.C., \& GROOM, A.C. (1983) Circulatory pathways in the sinusal spleen of the dog, studied by scanning electron-microscopy of microcorrosion cast. Journal of Morphology 178, 111-123.

STERNBERGER, L.A., HARDY, P.H., CUCULIS, J.J. \& MEYER, H.G. (1970) The unlabelled antibody enzyme method of immunohisto-chemistry preparation and properties of soluble antigen-antibody complex horseradish-D peroxidase antihorseradish-D peroxidase and its use in the identification of spirochetes. Journal of Histochemistry and Cytochemistry 18, 315-333.

STOERCKLÉ-BERGER, N., KELLER-BERGER, B., ACKERMAN, M., EHRENSPERGER, F. (1992) immunohistological diagnosis of rabbit haemorrhagic disease (RHD). Journal of Veterinary Medicine 39, 237-245.

UEDA, K., PARK, J.H., OCHIAE, K. \& ITAKURA, C. (1992) Disseminated intravascular coagulation (DIC) in rabbit haemorrhagic disease. Japanese Journal of Veterinary Research 40, 133-141.

XU, Z.J., \& CHEN, W.X. (1989) Viral haemorrhagic disease in rabbits: A review. Veterinary Research Communications 13, 205-212.

Accepted November 20, 1999 